\title{
Preparation of an Estuarine Sediment Quality Control Material for the Determination of Trace Metals
}

\author{
Vanessa Hatje, * Denilson S. S. dos Santos and Maria das Graças A. Korn \\ Instituto de Química, Universidade Federal da Bahia, 40170-290 Salvador-BA, Brazil
}

\begin{abstract}
Os materiais de controle de qualidade (QCM) têm sido usados rotineiramente no trabalho de laboratório, para preencher a lacuna entre a necessidade e disponibilidade de materiais de referência certificados (CRM). Os QCMs possuem custos relativamente baixos, quando comparados aos materiais de referência certificados (CRMs), sendo uma alternativa viável para a implementação de um sistema de controle de qualidade em laboratórios de várias áreas. Este trabalho descreve a produção de um QCM para determinação de metais em sedimentos estuarinos e os resultados de um exercício interlaboratorial. Estudos de homogeneidade e estabilidade foram realizados, e análises de variância foram aplicadas aos dados. As concentrações de Co, $\mathrm{Cu}, \mathrm{Cr}, \mathrm{Ni}, \mathrm{Mn}, \mathrm{Pb}$ e $\mathrm{Zn}$, dentro e entre recipientes não foram significativamente diferentes. $\mathrm{As}$ condições de armazenagem e temperatura não promoveram variação nos resultados. O QCM produzido foi considerado estável e homogêneo, e pode ser utilizado em cartas de controle de qualidade, avaliação da reprodutibilidade e exercícios interlaboratoriais.
\end{abstract}

Quality Control Materials (QCM) have being used routinely in daily laboratory work as a tool to fill the gap between need and availability of Certified Reference Materials (CRM). The QCM are a low-cost alternative to CRMs, and they are in high demand, especially, for the implementation of quality control systems in laboratories of several areas. This paper describes the preparation of a QCM for the determination of trace metals in estuarine sediments and the results of an interlaboratory exercise. Homogeneity and stability studies were performed and analysis of variance was carried out with the results. No statistical significant differences were observed in the concentrations of $\mathrm{Co}, \mathrm{Cr}, \mathrm{Cu}, \mathrm{Mn}, \mathrm{Pb}$ and $\mathrm{Zn}$ between- or within bottle results. Neither the storage nor temperature affected the results. Therefore, the QCM produced is considered homogeneous and stable and can be used for statistical control charts, evaluation of reproducibility and interlaboratory exercises.

Keywords: quality control material, sediments, trace metals

\section{Introduction}

Reliable environmental monitoring arising from chemical measurements is of vital importance for sound decision making across a wide spectrum of activities. The impact of the results provided by analytical measurements on the economy of countries is of increasing importance, and the quality of these measurements must be rigorously guaranteed if the ensuring beneficial effects are to be fully exploited. Nevertheless, the technological delay in terms of metrology, observed in developing countries, e.g. Brazil, is estimated to be around one hundred years. ${ }^{1}$ The National Institute of Standard and Technology (NIST), main organ of metrology of the USA, started the

*e-mail: vhatje@ufba.br production of reference materials in the beginning of the $20^{\text {th }}$ century. ${ }^{1}$ In Brazil, the production of certified reference materials only began in the 80 's, through a partnership between the Institute of Technological Research of São Paulo State (IPT) and NIST. The IPT is the only institution in Brazil, recognized internationally, that produces certified reference materials. ${ }^{2}$

Not surprisingly, the awareness regarding quality assurance (QA) and quality control (QC) for environmental analyses has increased considerably within the past few years. Laboratories are becoming more aware of the need to implement quality control protocols to verify levels of accuracy obtained. Guidelines, proficiency tests and intercalibration exercises have been extensively produced. ${ }^{3}$ However, all QA/QC procedures are not systematically followed by 
laboratories, and many examples from interlaboratory studies have demonstrated a clear lack of accuracy for parameters usually considered in environmental monitoring programs, e.g. trace metals and organic compounds. ${ }^{4}$ A lack of reliability in environmental analyses does not allow responding public concern with respect to environmental issues, and may create strong economic losses due to misuse of inaccurate data and consequent burdens. Problems associated to QC are all more acute when it involves variables, which pose great analytical difficulties (e.g. lower concentrations in samples of very complex matrices). This is the case of some toxic and carcinogenic substances usually determined in environmental monitoring, that are present in the environment in concentrations ranging from background to highly contaminated levels.

The certified reference materials (CRM) have been playing an important role in the verification of the accuracy of analytical measurements. The CRMs are used, especially, for instrumentation calibration, checking the performance of instruments against specification, qualitative analysis and quantitative validation of methodologies. However, there is a lot of confusion involving many aspects of CRMs, including their definitions and uses. Results from studies involving 1600 laboratories in 18 countries $^{5}$ indicated the following problems: (i) Confusion between definitions of CRM and non-certified reference materials; (ii) lack knowledge of uses, representativeness, and need of fit-for-purpose; (iii) lack of resources to implement quality systems; (iv) wrong perceptions of the costs of CRMs.

Reference material (RM), according to ISO, ${ }^{6}$ is a 'material or substance one or more of whose property values are sufficiently homogeneous and well established to be used for the calibration of an apparatus, the assessment of a measurement method, or for assigning values to materials'. A Reference Material that has its concentrations certified by a procedure which establishes its traceability to an accurate realization of the unit in which the property values are expresses, is called Certified Reference Material (CRM). ${ }^{6}$ The CRM is accompanied by a certificate that indicates the certified values of one or more properties, accompanied by an uncertainty at a stated level of confidence.

On the other hand, there are the non-certified reference materials, also known as laboratory reference materials (LRM) or quality control material (QCM). The main attributes of such materials are the homogeneity and the stability, which will guarantee the proper use of the material. Compared to CRM the accuracy is not as important, because its application aims a different purpose.
In this way, QCMs can be seen as a complementary instrument in the QA/QC laboratory programs, which not only can be used on a regular basis in the establishment of quality control charts to evaluate the long-term reproducibility of a method or laboratory, but also can be used in proficiency interlaboatory testing.

In this paper, the steps of preparation (i.e. collection, processing and analysis) of an estuarine sediment QCM for trace metals are described. The QCM preparation took in account recommendations of a guideline for the production of reference materials ${ }^{7}$ and ISO guides. Which the purpose to make laboratories aware of the importance of external quality control practices, the sediment prepared was used in a pilot national interlaboratory exercise for the determination of $\mathrm{Cr}, \mathrm{Cu}, \mathrm{Pb}, \mathrm{Zn}, \mathrm{Ni}$ e Mn. All the laboratories involved are commercial and/or research laboratories monitoring trace metal levels in sediment samples.

The implementation of $\mathrm{QA} / \mathrm{QC}$ procedures is extremely necessary and overdue in third world countries, and the preparation of a QCM is a very useful part of this important work.

\section{Experimental}

\section{Reagents}

All chemical used in the analyses were of analyticalreagent grade. Nitric acid 65\% m/v (Merck, Darmstadt, Germany), was used for the digestion of the samples. Calibration curves were obtained after appropriate dilution of $1000 \mathrm{mg} \mathrm{L}^{-1}$ multielement solution (ICP Multielement Standard IV, Merck, Darmstadt, Germany). Nitric acid $(0.1 \% \mathrm{v} / \mathrm{v})$, prepared in high-purity water (electrical resistivity $18 \mathrm{M} \Omega \mathrm{cm}^{-1}$ ) produced with a Milli-Q system (Millipore, MA, USA) was used for all dilutions. Plastic and glassware materials were cleaned by soaking in $10 \%$, $\mathrm{v} / \mathrm{v}, \mathrm{HNO}_{3}$ for at least $24 \mathrm{~h}$, and then rinsed three times with Milli-Q water.

\section{Instrumentation}

Elemental determination was carried out by Inductively Coupled Plasma Optical Emission Spectrometry (ICP OES) VISTA-PRO (Varian, Mulgrave, Australia). This instrument is equipped with a cyclonic spray chamber, a concentric nebulizer and a solid-state detector that allows measurements from 167 to $785 \mathrm{~nm}$. The pre-optical systems are purged with argon in order to enable readings below $180 \mathrm{~nm}$. The polychromator was thermostated at $34^{\circ} \mathrm{C}$ and purged with argon. An 
end-on gas interface was used to minimize interferences caused by self-absorption and recombination, to provide a wide linear dynamic range and low background. The instrumental operating parameters and the wavelengths used are given in Table 1.

Table 1. Operational parameters used in axial view ICP OES

\begin{tabular}{|c|c|c|}
\hline \multicolumn{3}{|l|}{ Operational parameter } \\
\hline $\mathrm{RF}$ power $(\mathrm{kW})$ & 1.2 & \\
\hline Plasma gas-flow rate $\left(\mathrm{L} \mathrm{min}^{-1}\right)$ & 15.0 & \\
\hline Auxiliary gas-flow rate $\left(\mathrm{L} \mathrm{min}^{-1}\right)$ & 1.5 & \\
\hline Nebulizer gas-flow rate $\left(\mathrm{L} \mathrm{min}^{-1}\right)$ & 0.8 & \\
\hline Sample flow-rate $\left(\mathrm{mL} \mathrm{min}{ }^{-1}\right)$ & 0.8 & \\
\hline \multirow[t]{4}{*}{ Emission lines $(\mathrm{nm})$} & Co II 230.786 & Ni II 230.300 \\
\hline & Cr II 267.716 & $\mathrm{~Pb}$ II 220.353 \\
\hline & $\mathrm{Cu} \mathrm{I} \quad 327.397$ & Zn I 213.857 \\
\hline & Mn II 257.611 & \\
\hline
\end{tabular}

\section{Sample collection}

Sediment samples had to have trace metal concentrations relatively high to be easily determined with a good precision and to reflect some degree of contamination, once most of sites currently studied in our research group have such characteristics. Based on pilot studies in estuarine sediments of Todos os Santos Bay, northeast Brazil, three sampling locations were chosen to meet the concentration requirements. In each candidate site, about $5 \mathrm{~kg}$ of wet sediment material was collected with a Van Veen grab. Care was taken to collect only the first $5 \mathrm{~cm}$ of surface oxic sediment.

\section{Preparation of sediments}

A flow chart of QCM preparation is presented in Figure 1. Sediments were wet sieved in $63 \mu \mathrm{m}$ nylon mesh, in the field, using water from the same sampling site where the sediments were collected, in order to minimize changes in the physical-chemistry of sediments. After sieving, samples were conditioned in acid cleaned polyethylene containers and taken to the laboratory. The sediment was air dried at ambient temperature for several weeks. Then, the material was dried, further, at $40{ }^{\circ} \mathrm{C}$ for approximately 120 hours. The dried sediments were ground to a fine powder using a pestle and mortar, and the material was passed through a $600 \mu \mathrm{m}$ and $120 \mu \mathrm{m}$ nylon sieve. The material retained in the sieves was crushed and grounded again following sieving through 600 and $120 \mu \mathrm{m}$ nylon sieves. The material was then inserted in a mixing drum, and it was kept rotating for $110 \mathrm{~h}$, until a sufficiently homogeneous material was obtained. Around $1.3 \mathrm{~kg}$ of sediment was made available for bottling. The bottling procedure was carried out in a stepwise manner, i.e. ten pre-cleaned polyethylene bottles were filled with around $20 \mathrm{~g}$ portions while the drum was stationary, then the drum was rotating again for $1 \mathrm{~min}$ and 10 other bottles were filled, until all material has being conditioned.

About $250 \mathrm{mg}$ of sediment samples were digested in Teflon Parr bombs using concentrated $\mathrm{HNO}_{3}$ for $16 \mathrm{~h}$ at a temperature of $120 \pm 5{ }^{\circ} \mathrm{C}$. Trace metals (i.e. $\mathrm{Co}, \mathrm{Cr}, \mathrm{Cu}$, $\mathrm{Pb}, \mathrm{Mn}, \mathrm{Ni}$ and $\mathrm{Zn}$ ), were determined by ICP OES.

The precision and accuracy of the analytical technique were assessed by analysis of an International Reference Material, MESS-2 (National Research Council of Canada) with each batch of samples. The average and standard deviation of the results of the reference material analyses are given in Table 2. Results indicate good analytical precision, but incomplete digestion (58-87\%) for the employed procedure. These results were not unexpected since the digestion procedure was not total, i.e. did not include hydrofluoric acid.

Table 2. Average $\left(\mathrm{mg} \mathrm{kg}^{-1}\right)$ and standard deviation obtained for 4 replicates of the standard reference material MESS-2 and detection limits

\begin{tabular}{lccc}
\hline Metal & $\begin{array}{c}\text { Measured } \\
\left(\mathrm{mg} \mathrm{kg}^{-1}\right)\end{array}$ & $\begin{array}{c}\text { Certified } \\
\left(\mathrm{mg} \mathrm{kg}^{-1}\right)\end{array}$ & $\begin{array}{c}\text { Detection limits } \\
\left(\mathrm{mg} \mathrm{kg}^{-1}\right)\end{array}$ \\
\hline $\mathrm{Co}$ & $11.9 \pm 0.5$ & $13.8 \pm 1.4$ & 0.0042 \\
$\mathrm{Mn}$ & $300 \pm 2.5$ & $365 \pm 21$ & 0.35 \\
$\mathrm{Cr}$ & $88.0 \pm 1.0$ & $106 \pm 8$ & 0.0039 \\
$\mathrm{Ni}$ & $36.8 \pm 1.7$ & $49.3 \pm 1.8$ & 0.0084 \\
$\mathrm{~Pb}$ & $12.8 \pm 1.1$ & $21.9 \pm 1.2$ & 0.017 \\
$\mathrm{Zn}$ & $139 \pm 1.8$ & $172 \pm 16$ & 0.0011 \\
$\mathrm{Cu}$ & $28.2 \pm 1.5$ & $39.3 \pm 2$ & 0.0061 \\
\hline
\end{tabular}

Based on the results of the pilot studies, the concentration level of trace metals and amount of remaining sample after pre-treatment, the sample BTS, collected in the São Jorge Channel, Todos os Santos Bay $\left(12^{\circ} 49^{\prime} 079 \mathrm{~S}, 38^{\circ} 45^{\prime} 147 \mathrm{~W}\right)$, was chosen for being the candidate that better fitted-the-purpose for a quality control material. The homogeneity and stability tests were performed only in the sample BTS.

\section{Homogeneity test}

There are no definitive rules for homogeneity tests as a number of samples to be analyzed. ${ }^{7}$ Nevertheless, homogeneity has to be carefully verified to ensure that the contents within bottle and from bottle to bottle are the same. For this study, 10 bottles were set aside, from the total batch of 66 bottles, for the homogeneity test between-bottles. Bottles were selected at regular basis during the bottling procedure. The bottles for betweenbottles homogeneity test were analyzed in triplicates and 


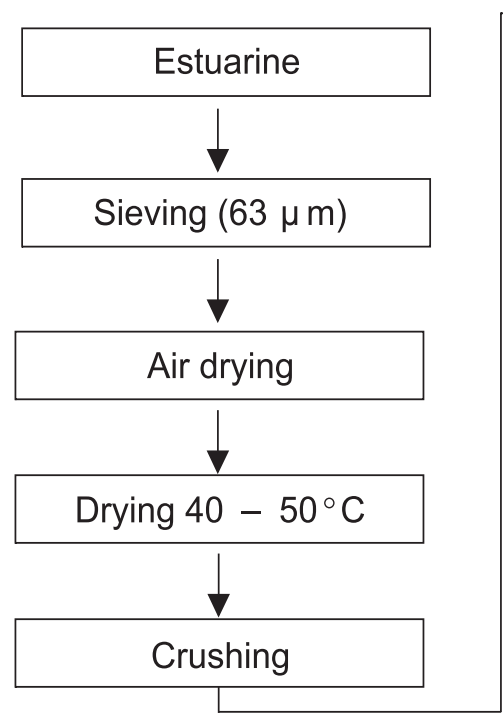

Figure 1. Flow chart for the preparation of estuarine QCM.

one-way analysis of variance (ANOVA), using the program GMAV-5, was performed to test sediment homogeneity. For the within-bottle homogeneity test 10 replicate determinations of all elements were performed in one bottle selected at random. Homogeneity tests were performed in $250 \mathrm{mg}$ sample intake.

\section{Stability test}

The characteristics of the quality control material should remain unchanged over long periods of time. The stability should be estimated by evaluating the behavior of the reference material under extreme conditions, i.e. simulating unusual temperature conditions that can occur during transport of the material, for example. It is predicted that this extreme condition would accelerate alteration and/or deteriorization of the material, hence reducing its shelf time.

The stability of the contents of the BTS sample was tested to verify its suitability as candidate quality control material. Three series of bottles were each stored at $4{ }^{\circ} \mathrm{C}$, ambient temperature $\left(20-25{ }^{\circ} \mathrm{C}\right)$, and $40{ }^{\circ} \mathrm{C}$. Triplicate samples were analyzed after storage, in the above conditions during 60 days.

\section{Intercalibration exercise}

Two samples were sent to each of the 15 laboratories that participated in the intercalibration exercise. The laboratories analyzed a minimum of five independent replicate determinations using the QCM prepared (SETS1). It was also send to each laboratory aliquots of the certified reference material MESS-2, and it was requested to them to make at least duplicate determinations. The performance of the method carried out by each laboratory was verified by the results of the MESS-2. The techniques of final determination used by the participating laboratories were: FAAS (flame atomic absorption spectrometry); ICP OES (inductively coupled plasma optical emission spectrometry); GF AAS (graphite furnace atomic absorption spectrometry). The pretreatment procedures often varied in details (e.g. addition of acid and decomposition time).

\section{Results and Discussion}

\section{Homogeneity tests}

Table 3 shows the coefficient of variation $(\mathrm{CV})$ of the homogeneity test between and within units. For the 10 bottles analyzed in triplicate, homogeneity between and within units was tested using analysis of variance (ANOVA).

In order to apply ANOVA to a data set, several assumptions need to be satisfied. The assumptions are: (i) independence of data within and among samples; (ii) normality of data; (iii) homogeneity of variances. The independence of data was assured by the experimental design employed. The normality of data was checked by statistical tests of kurtosis and skewness. The homogeneity of variances was verified by Cochran's test.

The Cochran's test applied to verify between bottles homogeneity was significant $(\mathrm{P}<0.05)$ for $\mathrm{Mn}$ and $\mathrm{Ni}$. No transformation was possible to eliminate heterogeneity. In such cases, it is still recommended to proceed with the 
Table 3. Coefficient of variability for between bottles and within bottles homogeneity tests

\begin{tabular}{lccccccc}
\hline Elements & $\mathrm{Cr}$ & $\mathrm{Zn}$ & $\mathrm{Ni}$ & $\mathrm{Co}$ & $\mathrm{Cu}$ & $\mathrm{Mn}$ & $\mathrm{Pb}$ \\
\hline $\mathrm{7V}(\%)$ & 1.2 & $\begin{array}{l}\text { between bottles } \\
\text { a }\end{array}$ & $\begin{array}{l}\text { within bottles } \\
\text { b }\end{array}$ & 1.5 & 2.0 & 1.8 & 3.4 \\
$\mathrm{CV}(\%)$ & 1.3 & 1.1 & 2.3 & 1.9 & 0.9 & 1.5 & 1.3 \\
\hline
\end{tabular}

a 10 bottles, $n=3$; ${ }^{\mathrm{b}} 1$ bottle, $\mathrm{n}=10$.

ANOVA, if the experimental design is balanced. ${ }^{8}$ That is because ANOVA is quite robust to departure from the homogeneity of variances assumption.

It turned out that Mn did not presented significant variation among units. This is a valid conclusion not only due to the fact that the experimental design employed was balanced, but also because the heterogeneity of variances leads to increased probability of Type I error. Therefore, if no significant differences occur among the means, one cannot make a Type I error, which is an erroneous rejection of a null hypothesis.

Nevertheless, for Ni there was a significant difference among means according to the ANOVA. This may be an erroneous result and should be interpreted with caution. Trace metals present different speciation and particle size associations in sediments. Hence, any segregation of particles may result in inhomogeneity regarding trace metal distributions. Although re-homogenization prior to each sub-sampling was realized, some inhomogeneity may still be present in Ni contents. For $\mathrm{Co}, \mathrm{Cr}, \mathrm{Cu}, \mathrm{Pb}$ and $\mathrm{Zn}$ there was no significant difference $(\mathrm{P}>0.05)$ in concentrations between different bottles, i.e. all concentrations were comparable.

The CV (Coefficient of Variation) within bottle homogeneity was comparable to between bottle homogeneity, including for $\mathrm{Ni}$, and the CVs were considerably smaller than the $\mathrm{CV}$ of the analytical method, considered being $5 \%$. Values of CVs well above $5 \%$ have been currently observed in the preparation of soil e sediment reference materials. ${ }^{9,10}$

The sediments analyzed proved to be homogeneous between and within bottles, i.e. there were no significant differences at a confidence level of $95 \%$ with a minimum sample intake of $250 \mathrm{mg}$ for $\mathrm{Co}, \mathrm{Cr}, \mathrm{Cu}, \mathrm{Pb}, \mathrm{Mn}$ and $\mathrm{Zn}$.

\section{Stability tests}

The contents of reference materials should remain unchanged over long periods of time, and the stability of the material will determine its shelf life. For the stability tests the assumption made was that at $4{ }^{\circ} \mathrm{C}$ changes, of any kind, proceed slowly. Hence, samples stored at $4{ }^{\circ} \mathrm{C}$ were used as reference for the samples stored at $20-25{ }^{\circ} \mathrm{C}$ and $40{ }^{\circ} \mathrm{C}$. The results of stability tests can be expressed as the relative variations, ${ }^{11,12}$ observed:

$\mathrm{R}_{\mathrm{T}}=\overline{\mathrm{X}}_{\mathrm{T}} / \overline{\mathrm{X}}_{4^{\circ} \mathrm{C}}$

where $\mathrm{R}_{\mathrm{T}}$ is the ratio of the mean value of measurements made at $20-25$ and $40{ }^{\circ} \mathrm{C}$, respectively, $\bar{X}_{T}$, and the mean value of measurements made simultaneously on samples stored at $4{ }^{\circ} \mathrm{C}, \overline{\mathrm{X}}_{4^{\circ} \mathrm{C}}$. The uncertainty $\mathrm{U}_{\mathrm{T}}$ of the ratio $\mathrm{R}_{\mathrm{T}}$ was obtained from the coefficient of variation of each set of measurements by the equation, ${ }^{12}$

$\mathrm{U}_{\mathrm{T}}=\left(\mathrm{CV}_{\mathrm{T}}^{2}+\mathrm{CV}^{2}{ }_{4{ }^{\circ} \mathrm{C}}\right)^{1 / 2} \mathrm{R}_{\mathrm{T}} / 100$

where $\mathrm{CV}_{\mathrm{T}}$ and $\mathrm{CV}_{4^{\circ} \mathrm{C}}$ are the coefficient of variation of $\mathrm{X}_{\mathrm{T}}$ and $\mathrm{X}_{4^{\circ} \mathrm{C}}$, respectively.

If the temperature has no effect on the concentration, then the measured ratios should be randomly distributed around one with a spread depending on the repeatability of the method. Moreover, the value 1 should be comprised between $R_{T}-U_{T}$ and $R_{T}+U_{T}$ for the samples be considered stable under the storage conditions used. Values of $R_{T}$ and $U_{T}$ for the studied elements can be seen in Table 4. In all cases studied, the values of $R_{T}$ were not significantly different from 1 at the confidence level of $95 \%$. There is no evidence of instability of the elements studied at room temperature and at $40{ }^{\circ} \mathrm{C}$. It can be expected that the longterm stability of this material is good and the shelf life of the material can be even longer than the period tested.

Table 4. Values of $R_{T}$ and $U_{T}$ found for stability test at $20-25$ and $40{ }^{\circ} \mathrm{C}$ for the studied trace metals

\begin{tabular}{lccccccc}
\hline Elements & $\mathrm{Cr}$ & $\mathrm{Zn}$ & $\mathrm{Ni}$ & $\mathrm{Co}$ & $\mathrm{Cu}$ & $\mathrm{Mn}$ & $\mathrm{Pb}$ \\
\hline \multicolumn{7}{c}{$20-25^{\circ} \mathrm{C}$} \\
$\mathrm{R}_{\mathrm{T}}$ & 1.01 & 0.97 & 1.06 & 0.99 & 1.00 & 0.99 & 0.98 \\
$\mathrm{U}_{\mathrm{T}}$ & 0.024 & 0.024 & 0.039 & 0.012 & 0.045 & 0.013 & 0.047 \\
& & \multicolumn{7}{c}{$40^{\circ} \mathrm{C}$} \\
$\mathrm{R}_{\mathrm{T}}$ & 1.00 & 0.98 & 0.99 & 1.03 & 1.03 & 0.99 & 0.93 \\
$\mathrm{U}_{\mathrm{T}}$ & 0.016 & 0.018 & 0.031 & 0.042 & 0.016 & 0.014 & 0.049 \\
\hline
\end{tabular}

Interlaboratory exercise

Proven that the requirements of stability and homogeneity, between and within units, at a minimum sample intake of $250 \mathrm{mg}$ have been fulfilled, the QCM was distributed to fifteen laboratories with the guaranty that each participant would analyze the same sample. The reproducibility and the between-laboratory standard deviation were assessed. Additionally to the QCM, with the use of MESS-2 it was possible to assess the accuracy of the results from participants. 
A series of problems were detected in the interlaboratory exercise. The first problem with the interlaboratory exercise was the lack of commitment. Only eight out of fifteen participants returned the results. As this interlaboratory exercise was a pilot study, the number of results received was enough for a screening assessment, nevertheless a greater number of laboratories must be included in a future proficiency test to have a more robust and representative exercise result. It is suspected that some participants were afraid of fail, even thought it was explained to them the objectives of the exercise and also emphasized to all participants that the identity of each laboratory would be preserved. This point will need to be worked out for future exercises. Another problem encountered in the interlaboratory exercise was the limited number of techniques employed by the participants. In this case, it will be really difficult to find a solution because most laboratories that analyze environmental samples in Brazil employ FAAS, GFAAS or ICP OES. For these spectrometric methods one of the main sources of errors may be in the digestion of the sample, which is not necessary in the neutron activation analysis (INAA), for example. Hence, the results of the pilot interlaboratory exercise could not be checked if results were affected by a systematic bias. The inclusion of international laboratories that employ different techniques will be necessary for the next interlaboratorial exercise.

The range of results for MESS-2 for the laboratories that employed HF were, in terms of percentage of recovery

Table 5. Means $\left(\mathrm{mg} \mathrm{kg}^{-1}\right)$ and coefficient of variation, in brackets, of interlaboratory exercise

\begin{tabular}{lccccccc}
\hline Elements & $\mathrm{Cr}$ & $\mathrm{Zn}$ & $\mathrm{Ni}$ & $\mathrm{Co}$ & $\mathrm{Cu}$ & $\mathrm{Mn}$ & $\mathrm{Pb}$ \\
\hline Laboratory 1 & 85.8 & 78.8 & 28.3 & 17.8 & 12.2 & 258 & 22.0 \\
& $(0.81)$ & $(1.46)$ & $(1.20)$ & $(1.04)$ & $(0.52)$ & $(0.34)$ & $(3.72)$ \\
Laboratory 2 & 123 & 52.6 & 26.7 & 12.9 & 18.3 & 321 & $\mathrm{nd}$ \\
& $(4.62)$ & $(5.66)$ & $(8.78)$ & $(14.1)$ & $(3.07)$ & $(1.99)$ & \\
Laboratory 3 & 88.6 & 60.6 & 20.7 & $\mathrm{nd}$ & 5.71 & 158 & 22.2 \\
& $(2.06)$ & $(1.74)$ & $(5.91)$ & & $(9.42)$ & $(8.95)$ & $(3.41)$ \\
Laboratory 4 & 98.0 & 101 & 38.2 & 13.3 & 21.1 & 344 & $\mathrm{nd}$ \\
& $(1.96)$ & $(2.65)$ & $(1.68)$ & $(1.90)$ & $(1.17)$ & $(2.01)$ & \\
Laboratory 5 & $\mathrm{bd}$ & 86.5 & $\mathrm{bd}$ & $\mathrm{bd}$ & $\mathrm{bd}$ & $\mathrm{bd}$ & $\mathrm{bd}$ \\
& & $(2.34)$ & & & & & \\
Laboratory 6 & 140 & 89.5 & 61.7 & 9.28 & 19.6 & 311 & $\mathrm{nd}$ \\
& $(12.7)$ & $(1.69)$ & $(16.3)$ & $(2.63)$ & $(0.70)$ & $(1.03)$ & \\
Laboratory 7 & 53.7 & 64.7 & 26.3 & 11.7 & 17.7 & 250 & 51.4 \\
& $(7.96)$ & $(3.19)$ & $(5.19)$ & $(4.43)$ & $(2.92)$ & $(0.67)$ & $(7.10)$ \\
Laboratory 8 & $\mathrm{nd}$ & 70.4 & $\mathrm{nd}$ & 16.8 & 14.3 & $\mathrm{nd}$ & $\mathrm{nd}$ \\
& & $(1.85)$ & & $(1.78)$ & $(2.80)$ & & \\
\hline
\end{tabular}

nd = not determined; bd = below detection . of the certified value: $\mathrm{Cr}, 85-126 ; \mathrm{Zn}, 74-102 ; \mathrm{Ni}, 57-$ 150; Co, 71-133; Cu, 30-98; Mn, 60-77. Only two laboratories submitted results for $\mathrm{Pb}$, which along $\mathrm{Co}$ presented poor results. This is ascribed to the low contents of $\mathrm{Pb}$ and $\mathrm{Co}$ compared to other elements. The $\mathrm{CV}$ s for the MESS-2 determinations varied from 0.1 to 24 . Nevertheless there is a clear pattern in the results, i.e. laboratories that had good recoveries for the CRM (MESS2) also presented CVs values below $5 \%$.

The results for the QCM are presented in Table 5. The great majority of CVs were below $5 \%$. The laboratories that presented low recoveries for MESS, also presented discrepant results for the QCM. Systematic and random errors are possible due to calibration errors, a lack of compliance with a single protocol, contamination, among others. It was recognized that a more clear set of instructions, i.e. a standard protocol, including sample preparation, digestion, calibration procedures, should be implemented to improve between-laboratory agreement. The way this pilot exercise was set, the variety of extraction schemes (i.e. temperature, time and pressure differences) used, does not allow data to be comparable, hence creating problems for the interpretation of data. Nevertheless, it is very worrying that laboratories found very different results. For example, $\mathrm{Zn}$ concentrations varied from 52.6 to $101 \mathrm{mg} \mathrm{kg}^{-1}$; $\mathrm{Cr}$ varied from 85.8 to $140 \mathrm{mg} \mathrm{kg}^{-1}$. There was a laboratory that could not detect any elements apart from $\mathrm{Zn}$. That suggests the existence of serious problems in the QA/QC procedures, and they need to be addressed.

\section{Conclusions}

The results obtained in this study showed that the estuarine material prepared here is stable and homogeneous for $\mathrm{Cr}, \mathrm{Zn}, \mathrm{Co}, \mathrm{Cu}, \mathrm{Mn}$ e $\mathrm{Pb}$ at a minimum sample intake of $250 \mathrm{mg}$. This material can be considered a suitable tool to achieve a good laboratory quality control of trace metal determination in estuarine sediments and similar matrices. The QCM produced can be used to check repeatability of measurements and to carry out interlaboratory exercises.

The discrepant results obtained in the pilot interlaboratory exercise stress the need to improve quality controls for routine analysis, as well as, a better comprehension of the uses of QCM and CRM. The interlaboratory exercise will be repeated in the future to document improvement of laboratory performance. Prior to that, a discussion with all participants will try to identify the possible sources of errors that led to such poor performance and to establish standard protocols to all steps involved in metal analyzes. The fact that participants will 
know the matrix in the next interlaboratory exercise may, therefore, introduce bias in the results.

In this paper, it could be shown that the preparation of the QCM is quite simple. Good laboratory and fieldwork practice, following systematic clean procedures are the secrets for the achievement of good results. Moreover, to prepare QCM in the scale of this work, it is not necessary very expensive infrastructure and a great amount of resources, so a large number of laboratories would have the minimum facilities to make their own QCM at low costs. It was estimated that each $50 \mathrm{~g}$ unit of the prepared QCM cost less than U\$ 40.00, which is approximately one tenth of a CRM (e.g. NIST CRM 1646a). The price of a second QCM could be even lower if more material could be collected and treated simultaneously. The production of QCM is very appealing for laboratories, in the used of routine tests to the monitoring of quality control procedures. This is especially true for third world countries, where resources for research are very limited. Another advantage of the QCM is that it can closely match the samples currently analyzed by a specific laboratory. Nevertheless, it is necessary to emphasize that a QCM is not a substitute for a CRM and that the producer has to have a very rigorous procedure for checking and demonstrate the stability and homogeneity of the material.

\section{Acknowledgments}

Vanessa Hatje fellowship, Denilson S.S. dos Santos scholarship and this project were funded by CAPES. Maria das G. A. Korn fellowship was funded by CNPq.

\section{References}

1. Alves, N.P.; Moraes, N.D.; Analytica 2003, 3, 54.

2. http://www.inmetro.gov.br/laboratorios/labCredenciados.asp, accessed in February 2005.

3. Quevauviller, Ph.; Rauret, G.; López-Sánchez, J.-F.; Rubio, R.; Ure, A.; Muntau, H.; Sci. Total Environ. 1997, 205, 223.

4. Quevauviller, Ph.; Donard, O.F.X.; J. Environ. Monit. 1999, 1, 503.

5. Quevauviller, Ph.; Benoliel, M.J.; Andersen, K.; Merry, J.; TrAC, Trends Anal. Chem. 1999, 18, 376.

6. Quality System Guidelines for Production of Reference Materials, ISO Guide 30, International Standardization Organization: Geneva, 1992.

7. Guidelines for the Production and Certification of BCR Reference Materials, European Commission Document, European Commission: Brussels, 1994.

8. Underwood, A.J.; Experiments in Ecology, Cambridge Press: United Kindom, 1997.

9. Llauradó, M.; Torres, J.M.; Tent, J.; Sahuquillo, A.; Muntau, H.; Rauret, G.; Anal. Chim. Acta 2001, 445, 99.

10. Quevauviller, Ph.; Spectrochim. Acta, Part B 1998, 53, 1261.

11. Quevauviller, Ph.; Maier, E.A.; Griepink, B.; Fortunati, U.; Vercoutere, K.; Muntau, H.; TrAC, Trends Anal. Chem. 1996, 15,504 .

12. Wegener, J.W.M.; Cofino, W.P.; Maier, E.A.; Kramer, G.N; TrAC, Trends Anal. Chem 1999, 18, 14.

Received: April 7, 2005

Published on the web: February 17, 2006 